\title{
Importance of case definition to monitor ongoing outbreak of chikungunya virus on a background of actively circulating dengue virus, St Martin, December 2013 to January 2014
}

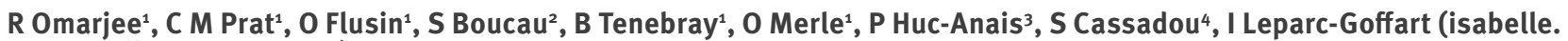
leparcgoffart@gmail.com) ${ }^{1}$

1. IRBA, French National Reference Center for Arboviruses, Marseille, France

2. Affaires Sanitaires et Sociales (ARS), Délégation territoriale de Saint Martin et Saint Barthélemy, Saint Martin, France

3. Laboratory Saint-Martin Biologie Philippe Chenal, Saint Martin, France

4. French Institute for Public Health Surveillance, Paris France

Citation style for this article:

Omarjee R, Prat CM, Flusin O, Boucau S, Tenebray B, Merle O, Huc-Anais P, Cassadou S, Leparc-Goffart I. Importance of case definition to monitor ongoing outbreak of chikungunya virus on a background of actively circulating dengue virus, St Martin, December 2013 to January 2014. Euro Surveill. 2014;19(13):pii=20753.

Available online: http://www.eurosurveillance.org/ViewArticle.aspx?Articleld=20753

Since 5 December 2013, chikungunya virus (CHIKV) has been demonstrated to circulate in the Caribbean, particularly on Saint Martin. This region is facing a concomitant dengue virus (DENV) outbreak. Of 1,502 suspected chikungunya cases, $38 \%$ were confirmed chikungunya and $4 \%$ confirmed dengue cases, with three circulating serotypes. We report in addition $2.8 \%$ CHIKV and DENV co-infections. This study highlights the importance of the case definition for clinicians to efficiently discriminate between DENV infection and CHIKV infection.

On 5 December 2013, the first confirmed autochthonous cases of chikungunya virus (CHIKV) infection were reported in the Caribbean, on the island of Saint Martin, by the French National Reference Center for Arboviruses (IRBA, Marseille) [1]. Before that time, only imported cases of Chikungunya had been detected in the Americas.

CHIKV is a mosquito-transmitted virus (arbovirus) of the Togaviridae family and Alphavirus genus. It was first isolated from humans and mosquitoes in 1952/53 during an epidemic of febrile polyarthralgia in Tanzania [2]. CHIKV is endemic in some parts of Africa and causes recurrent epidemic waves in Asia and on the Indian subcontinent.

The Caribbean region, with tropical climate and the presence of Aedes aegypti mosquito vectors is endemic for dengue virus (DENV), another arbovirus. Since the re-emergence of dengue in the Caribbean subregion in the 1970 s and the first dengue outbreak identified on Saint Martin in 1977, this arbovirus has been responsible for multiple waves of outbreaks on this island [3].
The latest epidemic of DENV on the island started in January 2013.

Both chikungunya and dengue disease have similar clinical symptoms, which makes the clinical diagnosis complex, although differences exist. In the context of an emerging virus in a region where another arbovirus is already endemic and actively circulating, the case definition (Table 1) is crucial to follow the dynamics of the new outbreak. This report shows the efficiency of the established case definition in the chikungunya outbreak on Saint Martin, and presents the incidence of co-infection of DENV and CHIKV.

\section{Virological findings during the}

\section{chikungunya and dengue outbreak}

The French National Reference Centre for Arboviruses in Marseille received all samples from Saint Martin fitting the CHIKV case definition. However, both DENV and

\section{TABLE 1}

Case definition for clinical suspected chikungunya and dengue cases, Saint Martin, 2013

\begin{tabular}{|l|l|}
\hline $\begin{array}{l}\text { Chikungunya virus } \\
\text { infection }\end{array}$ & Dengue virus infection \\
\hline $\begin{array}{l}\text { Fever higher than } 38.5 \\
\text { o } \text { of sudden onset }\end{array}$ & $\begin{array}{l}\text { Fever higher than } 38.5^{\circ} \mathrm{C} \text { of sudden } \\
\text { onset }\end{array}$ \\
\hline $\begin{array}{l}\text { Articular pain in } \\
\text { extremities }\end{array}$ & $\begin{array}{l}\text { At least one of the following clinical } \\
\text { signs: headache, arthralgia, myalgia, } \\
\text { back pain, retro-orbital pain, musculo- } \\
\text { articular pain }\end{array}$ \\
\hline $\begin{array}{l}\text { Absence of other } \\
\text { aetiological causes }\end{array}$ & Absence of other aetiological causes \\
\hline
\end{tabular}


TABLE 2

Strategy for laboratory diagnosis of chikungunya and dengue virus infection, Saint Martin, 2013

Period between start date of

clinical symptoms and sample Laboratory tests performed

$$
\text { date }
$$

\begin{tabular}{|l|l|}
\hline$<5$ days & Real-time RT-PCR \\
\hline Between 5 and 7 days & Real-time RT-PCR and serology \\
\hline$>7$ days & Serology \\
\hline
\end{tabular}

CHIKV diagnosis was done on every sample because of the local epidemiological context and the clinical similarities between the two diseases. According to the date of clinical symptoms onset and the sampling date, viral genome and/or IgM and IgG detection techniques were performed following the strategy described in Table 2, by using, respectively, real-time RT-PCR described previously $[4,5]$ and in-house ELISA (MAC ELISA for IgM and indirect IgG ELISA) [6]. The samples were mostly early samples, with $87 \%$ of samples taken less than seven days after the onset of symptoms.

The virological results are presented in Figure 1. A total of 1,502 suspected chikungunya cases samples were received between week 43 of 2013 (4 December 2013) and week 05 of 2014 (31 January 2014). Of those, 570 were confirmed chikungunya cases ( $38 \%$ ), and 65 were confirmed dengue cases ( $4 \%)$. Confirmed cases were defined as patients with RT-PCR-positive or IgM- and IgG-positive samples. The median age of confirmed chikungunya cases was 39 (range: 10 days-73) and $60 \%$ were female. There were only three severe cases which required hospitalisation.

In Saint Martin, three serotypes of DENV co-circulated during this outbreak: DENV1, DENV 2 and DENV4, with serotype 1 predominating. The proportion of the different DENV serotypes detected during this period is presented in Figure 2.

There were an additional 16 patients with confirmed co-infection of CHIKV and DENV (not included in Figure 1), i.e. with both viral genomes detected in the same blood sample. Those cases corresponded to the clinical case definition (Table 1) and were not severe cases. The co-infecting DENV was predominantly serotype 1 , following the distribution observed in the monoinfected patients with $10 D N_{1} V_{1}$, two DENV 2 and four $\mathrm{DENV}_{4}$ infections. Of these co-infected cases, four patients were two pairs of relatives living at the same address.

\section{Discussion}

The Caribbean region is currently facing an epidemic of CHIKV that started on Saint Martin and spread to Saint Barthelemy, Martinique, Guadeloupe and the Virgin Islands within a few weeks. This is the first time that CHIKV circulation has been demonstrated in the Caribbean area and, more generally, the Americas. The genome of this circulating CHIKV strain was sequenced and belongs to the Asian genotype, suggesting Asia as the probable origin for the circulating virus [7].

The concomitant presence of DENV on this island leads to a difficult differential diagnosis for clinicians because both infections have similar clinical signs. Here, shortly after the start of the outbreak, an efficient case definition was set up that allowed monitoring of the emerging CHIKV outbreak on the background of actively circulating DENV.

A non-negligible proportion of co-infections were identified. Patients co-infected with CHIKV and DENV were previously reported in India, South-East Asia and Africa [8-10]. During the chikungunya epidemic in Gabon in 2007, a total of $3 \%$ of CHIKV-infected patients were also infected with DENV, both viruses being detected by RT-PCR. The CHIKV strain in Gabon belonged to the East Central South African genotype, contrary to the present Saint Martin virus, which belongs to the Asian

\section{FIGURE 1}

Confirmed chikungunya $(n=570)$ and dengue $(n=65)$ cases, Saint Martin, 4 December 2013-31 January 2014

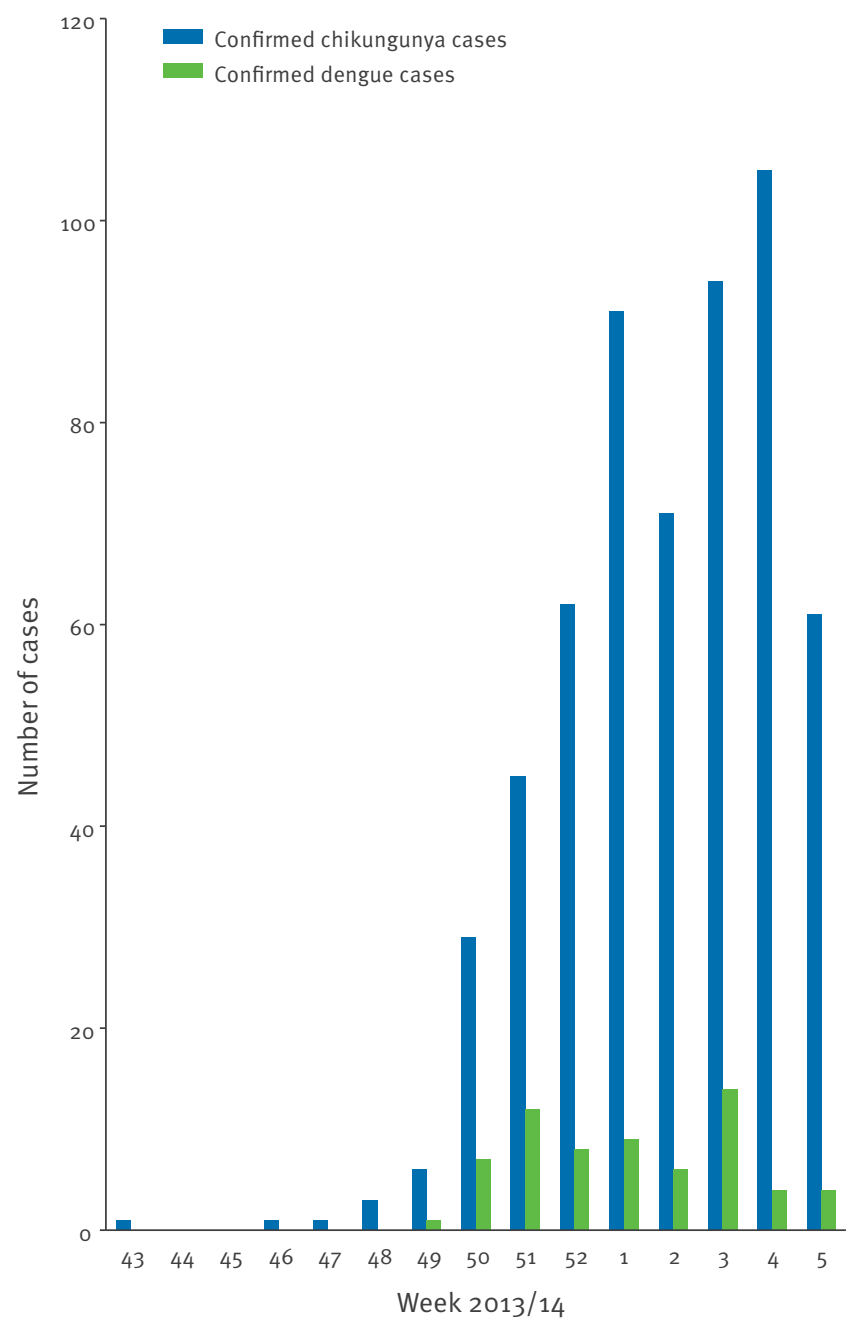


Distribution of circulating dengue virus serotypes, Saint Martin, 4 December 2013 to 31 January $2014(n=78)$

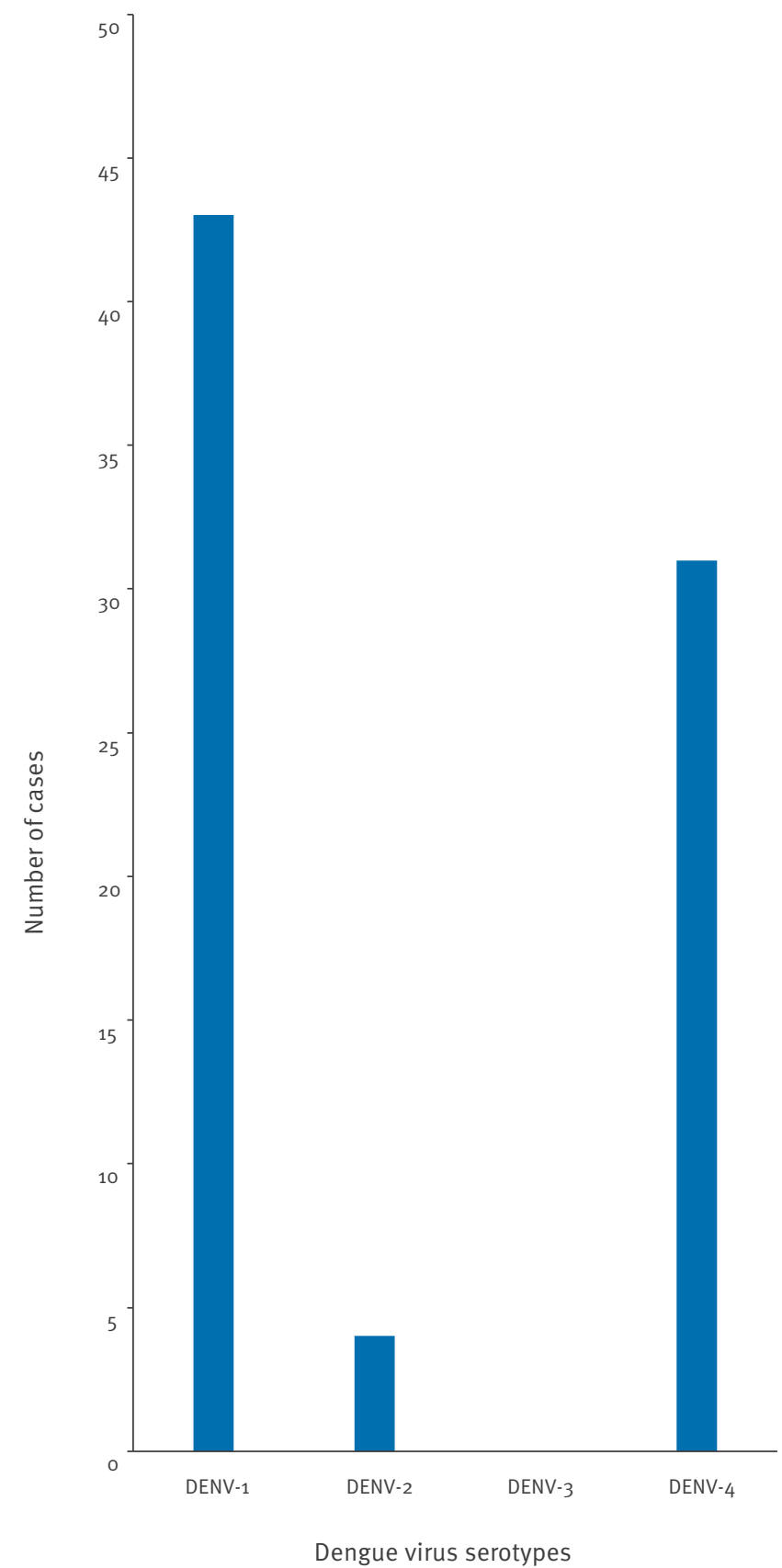

genotype. However, the number of co-infected cases in this current outbreak follows the same pattern, with $\mathbf{2 . 8 \%}$ of CHIKV-infected patients also infected by DENV.

This study documents the importance of a clear case definition set up for clinicians to efficiently discriminate between DENV infection and CHIKV infection, thereby allowing good monitoring of the emerging outbreak by health authorities. With the presence of Aedes mosquitos in most of the Americas, and intense circulation of the human population in this area, it is predicted that CHIKV will spread, and most probably in DENV-endemic areas.
Both emergences of dengue virus in France in 2010 and 2013 started with the arrival of a viraemic patient from the French Caribbean, which reflects the considerable exchange between Europe and the Caribbean $[11,12]$. The current chikungunya outbreak in the Caribbean likewise presents a threat of emergence of this disease in European countries, where the vector Aedes albopictus is already established.

Authors' contributions

RO, CMP, OF, SB, BT, OM, PH-A, SC and ILG participate to the study; RO, CMP, OF, ILG wrote the manuscript; PH-A and SC reviewed the manuscript.

\section{Conflict of interest:}

None declared.

References

1. Cassadou S, Boucau S, Petit-Sinturel M, Huc P, Leparc-Goffart I, Ledrans M. Emergence of chikungunya fever on the French side of Saint Martin island, October to December 2013. Euro Surveill. 2014;19(13): pii=20752.

2. Robinson M. An epidemic of virus disease in Southern Province, Tanganyika Territory, in 1952-53. I. Clinical features. Trans R Soc Trop Med Hyg. 1955;49(1):28-32. http://dx.doi. org/10.1016/0035-9203(55)90080-8

3. Van der Sar A, Woodall JP, Temmer LE. The dengue epidemic in the Leeward Islands of the Netherlands Antilles: Saba, St. Eustatius, and St. Martin, 1977. In: PAHO Scientific pub. Dengue in the Caribbean. Washington, DC: Pan American Health Organization; 1977. p. 55-9.

4. Pastorino B, Bessaud M, Grandadam M, Murri S, Tolou HJ, Peyrefitte CN. Development of a TaqMan RT-PCR assay without RNA extraction step for the detection and quantification of African Chikungunya viruses. J Virol Methods. 2005;124(12):65-71. http://dx.doi.org/10.1016/j.jviromet.2004.11.002

5. Leparc-Goffart I, Baragatti M, Temmam S, Tuiskunen A, Moureau G, Charrel R, et al. Development and validation of real-time one-step reverse transcription-PCR for the detection and typing of dengue viruses. J Clin Virol. 2009;45(1):61-6. http://dx.doi.org/10.1016/j.jcv.2009.02.010

6. Marchand E, Prat C, Jeannin C, Lafont E, Bergmann T, Flusin O, et al. Autochthonous case of dengue in France, October 2013. Euro Surveill. 2013;18(50):pii=20661.

7. Leparc-Goffart I, Nougairede A, Cassadou S, Prat C, de Lamballerie X. Chikungunya in the Americas. Lancet. 2014;383(9916):514. http://dx.doi.org/10.1016/S0140-6736(14)60185-9

8. Chahar HS, Bharaj P, Dar L, Guleria R, Kabra SK, Broor S. Coinfections with hikungunya virus and dengue virus in Delhi, India. Emerg Infect Dis. 2009;15(7):1077-80. http://dx.doi. org/10.3201/eid1507.080638

9. Leroy EM, Nkoghe D, Ollomo B, Nze-Nkogue C, Becquart P, Grard G, et al. Concurrent chikungunya and dengue virus infections during simultaneous outbreaks, Gabon, 2007. Emerg Infect Dis. 2009;15(4):591-3. http://dx.doi.org/10.3201/ eid1504.080664

10. Chang SF, Su CL, Shu PY, Yang CF, Liao TL, Cheng CH, et al. Concurrent Isolation of Chikungunya Virus and Dengue Virus from a Patient with Coinfection Resulting from a Trip to Singapore. J Clin Microbiol. 2010;48(12):4586-9. http://dx.doi. org/10.1128/JCM.01228-10

11. La Ruche $G$, Souarès $Y$, Armengaud A, Peloux-Petiot $F$, Delaunay $P$, Desprès $P$, et al. First two autochthonous dengue virus infections in metropolitan France, September 2010. Euro Surveill. 2010;15(39): pii=19676.

12. Marchand E, Prat C, Jeannin C, Lafont E, Bergmann T, Flusin O, et al. Autochthonous case of dengue in France, October 2013. Euro Surveill. 2013;18(50):pii=20661. 